Law and Society Review 32, 1 June 1998: 23-61.

\title{
RATIONAL CHOICE, SITUATED ACTION, AND THE SOCIAL CONTROL OF ORGANIZATIONSi
}

\author{
Diane Vaughan
}

\begin{abstract}
The legal and administrative apparatus responsible for the social control of organizations relies extensively on the deterrent effects of punishment. This strategy presumes a rational choice model of organizational misconduct that de contextualizes decision making, emphasizing consequences while ignoring how preferences are formed. I raise three challenges to the rational choice/ deterrence model of social control: 1) research and theory on decision making, 2) a sociological paradigm that situates individual action in a structure/ culture/ agency nexus that influences interpretation, meaning, and action at the local level, and 3) an analysis of the Challenger launch decision at NASA as situated action, showing how structure, culture, and history shaped preferences and choice. These challenges suggest a need to reorient regulatory activity toward the social context of decision making. I conclude with a research agenda to explore the relationship between situated action, preference formation, rational choice, and decisions to violate in organizational misconduct.
\end{abstract}

Management decisions in the business world that value competitive and economic success more highly than the well-being of workers, consumers, or the general public so often have come to public attention that today's most widely accepted model of corporate criminality portrays managers of profit-seeking organizations as "amoral calculators" whose illegal actions are motivated by rational calculation of costs and opportunities (Kagan and Scholz, 1984). D riven by pressures from the competitive environment, managers will violate the law to attain desired organizational goals unless the anticipated legal penalties (the expected costs weighed against the probability of delaying or avoiding them) exceed additional benefits the firm could gain by violation. The amoral calculator model locates the cause of business misconduct in the calculations of individual decision makers. It reflects the logic of sociological rational choice theory (Hechter, 1987; Friedman and Hechter, 1988; J.S. Coleman, 1990; Hechter and Kanazawa 1997), but with one important distinction. When decision makers' calculations of costs and benefits are tainted by self-interest, economics, or politics so that intentional 
wrongdoing and/ or harm result, their calculation becomes amoral.

The amoral calculator model also has wide acceptance as an explanation for the misconduct of other types of organizations that violate laws, administrative rules, and regulations. Though not corporate profit-seekers, in order to survive all organizations must compete for scarce resources (Pfeffer and Salancik, 1978; Vaughan, 1983: 54-66). Competition for scarce resources encourages research institutions to falsify data in order to win grants and prestige; universities to violate NCAA recruiting regulations in order to guarantee winning athletic teams; police departments to violate the law to make arrests that bring recognition and funding; political parties and governments to commit illegalities to secure national and international power. In response to competitive pressures emanating from the external environment, according to the amoral calculator model, individuals attempt to achieve organization goals through violative behavior. The lynch pin of the model's applicability to a variety of organizations is the violative behavior itself: because laws, rules, or administrative regulations forbid the behavior and carry penalties, decisions to violate appear to be imbued with intent, calculation of costs and benefits, and some degree of forethought about harmful consequences.

Punishment is considered an important tool for the social control of organizations because of institutionalized beliefs that the ultimate cause of organizational offending is rational actors who will include the costs of punishment in their calculations and be deterred from violative behavior. Most certainly, the legal and administrative apparatus for the social control of organizations utilizes diverse approaches (e.g., Clinard and Yeager, 1980; Bardach and Kagan, 1982; Simpson, 1992). D espite alternatives, however, punishment often is a key regulatory strategy, either for the organization, its responsible members, or both (e.g., Hawkins, 1984; Reiss, 1984; Braithwaite, 1985; 1989; Ayres and Braithwaite, 1992). The priority given a legalistic deterrence approach has persisted under two ironic conditions. First, research has produced little data about how decisions to violate are made. It may be true that in many circumstances, decisions to violate fit the amoral calculator model. But absent a body of research examining these decisions, strategies for control will rest on untested assumptions. Second, research has produced abundant data affirming regulatory ineffectiveness in controlling organizational misconduct (Stone, 1975; Coffee, 1977; 1981; Ermann and Lundman, 1978; Katz, 1979; Anderson, 1980; Diver, 1980; Wheeler and Rothman, 1982; Wheeler et al., 1982; Shapiro, 1984; Ewick, 1985; J.W. Coleman, 1987; Cullen et al., 1987; Vaughan, 1990; Weisburd et al., 1991). Regulators do regulate 
effectively in many specific cases, but this research indicates that the sources of regulatory failure are socially organized and systematic, so that across cases the efficacy of the legalistic deterrence model is undermined. Perhaps strategies other than punishment should be given greater consideration and priority.

In this paper, I take the position that the socio-legal research agenda should include efforts to develop greater understanding about the causes of organizational misconduct in order to lay a foundation for strategies for control that are maximally effective. The amoral calculator model de contextualizes decision making. However, the choices people make tend to be rational within situational contexts. Consequently, I argue for case studies that explore decisions to violate in naturalistic settings in order to investigate the link between social context and preference formation, the uncharted territory of rational choice theory (Hechter and Kanazawa, 1997). I support this position with research-based challenges to a rational choice/ deterrence model for the social control of organizations that justify a skeptical stance about its efficacy. First, I critique the socio-legal research that has reinforced the credibility of this model. Then, I draw from sociological theory that affirms an alternative model of human behavior as situated action, showing that a fully elaborated explanation of decision making necessarily would merge structure, culture, and agency. Next, I summarize my research on the 1986 Space Shuttle Challenger disaster (1996) because the data show that 1) the situated character of social action can shape choices in organizations so that deviance becomes normal and acceptable, rendering deterrent strategies ineffective, and 2) institutional and organizational forces influence what individuals consider rational at a given moment. Finally, I conclude by suggesting a research agenda to explore the relationship between situated action and organizational misconduct, so that its causes might be better understood.

\section{Research Challenges to the Rational Choice/ Detemence Model}

The tendency for the legal and administrative apparatus to prioritize a rational choice/ deterrence model for the social control of organizations no doubt originates in a belief fundamental to American culture: the value placed on individualism that locates responsibility for achievement, accountability, and responsibility in the single actor (de Tocqueville, 1969; Bellah et al. 1985). This cultural belief has been reinforced by socio-legal research on structural variables related to "white-collar" and other forms of organizational misconduct. 
Q uantitative studies using organizations as the units of analysis (usually corporations) consistently have identified a correlation between competition, economic strain, and violative behavior (Sutherland, 1949; Staw and Swajkowski, 1975; Clinard and Y eager, 1980; Simpson, 1986). The impossibility of micro-analysis in this research notwithstanding, the persistent relationship between economic strain and violative behavior has lent credibility to an amoral calculator model of decision making that goes like this: when an organization experiences structural strain to achieve its goals, individuals acting in their organization roles weigh the costs and benefits of their actions, choosing to violate laws and rules to attain organization goals.

Q uantitative research linking structural variables to outcomes is the most frequent strategy employed in sociological rational choice theory. Rational choice theory is, as Hechter and Kanazawa (1997) state, "...an inherently multilevel enterprise. It seeks to account for social outcomes on the basis of both social context and individual action (1997: 208)." However, the data and its interpretation remain at the aggregate level, for the theory does not attempt to explain what a rational person will do in a particular situation. Rational choice theorists consider both macro- and micro-level elements to be important determinants of outcomes, but empirical applications place greater emphasis on structural determinants for methodological reasons related to constraints on quantitative measurement of individual values and cognition (Hechter and Kanazawa, 1997: 193). Instead, sociological rational choice theorists make assumptions about individual cognitive capacities and values, often a subjective-expected utility model. Preference formation has no place in the theory, and as Hechter and Kanazawa conclude, "...the mechanisms for individual action in rational choice theory are descriptively problematic (1997: 195)."

What is true of sociological rational choice theory also holds for what is known about decision making in the violative behavior of organizations. Assumptions govern and conceal understanding about individual cognitive capacities and values: the amoral calculator model that has offenders calculating the costs and benefits of some known harmful act has remained a hypothesis, often invoked or assumed as an explanation, but seldom tested. This research failure is not a failure of interest or imagination; it is a failure of opportunity. D ifficult barriers exist to conducting research that explores how decisions to violate are made (Vaughan, 1992a). 
Absent a full-fledged, systematic research program, the few studies with data on decision making have been influential. The amoral calculator model received early support from G eis's (1967) classic case study of the heavy electrical equipment antitrust case, widely cited and reproduced in anthologies. Presenting the first in-depth view of executives' thoughts and perceptions about their violations, Geis quoted CEOs who stated they were aware of the illegality and its harmful social consequences as they colluded about pricefixing. Twenty years later another famous case affirmed the model. D ocum ents surfaced in the Ford Pinto case showing, in writing, Ford executives' calculation of costs and benefits in a redesign decision that juxtaposed the cost of redesign against the quantified loss of human life in accidents if the redesign were not done. Lives had already been lost; nonetheless, production continued (Cullen et al., 1987). Research based on interviews with managers also lent support to the model (Clinard, 1983; Jackall, 1988; Kram, Y eager, and Reed, 1989).

While suggestive and supportive, this evidence remains far from definitive. In the above projects, the researchers were pursuing multiple interests and questions in research informed by other perspectives. Their projects were not designed specifically to study decision making. Therefore, the relationship between the known structural correlates of misconduct - competition, scarce resources, institutionalized norms, organization characteristics, the regulatory environment - and decisions to violate was not part of the agenda (for these correlates, see e.g., J.W. Coleman, 1987; Kramer, 1992). Also, rather than studying the process of decision making as it occurred, data availability limited the research, of necessity, to retrospective accounts. A common research problem for this topic, missing still were data on decisions made in real time in organizations.

Nonetheless, socio-legal scholars long have argued that organizational offenders were susceptible to the deterrent effects of punishment (e.g., Zimring and Hawkins, 1973; Braithwaite and G eis, 1982; Braithwaite, 1985). This loyalty to the rational choice/ deterrence model for organizational offenders is buttressed by two additional beliefs held in the scholarly community (Simpson and Koper, 1992; Weisburd et al., 1995). First, in contrast to individuals who commit traditional crime, the so-called "white-collar" offender is believed to be more vulnerable to the costs of punishment because he or she has more to lose as a consequence: social status, job, money, comfortable home, family life (Braithwaite and G eis, 1982; Mann et al. 1982; Weisburd et al., 1991). 
This observation makes sense, but also is untested: no research has been done that compares the deterrent impact of sanctions on the perceptions of violators in formal organizations versus those of offenders who engage in street crime. Second, in contrast to street criminals, whose law-breaking often lacks planning and evidences spontaneity, organizational illegality appears to be a coolly instrumental act. This belief is supported by evidence of collective decision making in collusive actions (G eis, 1967; Baker and Faulkner, 1993) and recidivist violators (Sutherland, 1949; Clinard and Yeager, 1980): the routinization and patterning suggest intentional illegality and knowingly taking actions that do social harm in response to competitive pressures.

Are violations a result of rational calculation of costs and benefits of some harmful social act? Recently, scholars have attempted to map this unexplored terrain. Some have studied decision making indirectly by examining deterrence. Simpson and Koper (1992) analyzed recidivism of corporate offenders, finding weak support for deterrence. Weisburd et al. (1995), examining recidivism after incarceration of individual white-collar offenders, found no specific deterrent effect over a 126-month follow-up period. One project showed that legalistic deterrent strategies can have negative unintended consequences: G rabosky (1995: 351-353) reviewed several studies showing that in some cases a deterrent regulatory posture actually reduced compliance. Even when research examines decision making more directly, support for the amoral calculator model remains unimpressive. G rabosky (1989) analyzed seventeen case studies of misconduct by public sector organizations, finding evidence of careful assessment and weighing of costs and benefits in only two of the seventeen. Several studies used interviews to examine the deterrent effects of punishment on managerial decision making. Simpson concluded that "managers, for the most part, do not think in deterrence terms (1992: 303)." Briithwaite and Makkai (1991) found no support for deterrence. Paternoster and Simpson (1993; 1996) and Simpson (1998, forthcoming) tested deterrence in surveys that used offense-specific models of corporate crime in a vignette design. They found some indication of a deterrent effect in some situations.

At the same time that these recent interview-based studies break new ground with innovative approaches, they also demonstrate the difficulties of research on decision making and illegality. The research designs make the meaning of the results unclear. Testing the deterrent effects of punishment is the stated goal 
of this research. That individual decision makers knowingly and rationally calculate the costs and benefits of punishments is assumed at the outset, and becomes the basis for the design. Respondents not only are informed that the behavior in question is a violation, but also the researchers make the costs and benefits clear, conditions that seldom hold in real-life decision making in the workplace (Simon, 1957; 1976; Gross, 1978; Weick, 1979; 1995). Further, social context matters: organizational socialization, culture, financial dependence on the organization, and organizational mandates have known effects on the thoughts and actions of members (Van Maanen and Schein 1979; Finney and LeSieur, 1982; Van Maanen and Barley, 1985; Jackall, 1988; Martin, 1992). Consequently, a person responding to an interview, questionnaire, or vignette is not subject to the same contingencies as when making routine decisions in the workplace. The outcomes, which show either minimal or no deterrent effects, are taken by the researchers as challenges to the study design, not the de contextualized rational choice assumptions on which the designs are based.

Research raises additional reasons for questioning the priority of a rational choice/ deterrence model over other possible regulatory options. In contrast to the amoral calculator model, some managers violate for reasons other than instrumental action directly tied to achieving competitive success: incompetence, misunderstanding of laws, or improper attention to regulatory requirements (Kagan and Scholz, 1984). Also, how managers actually assess risks in the workplace is far from the systematic calculation the rational choice model implies: decision makers do not weigh all possible outcomes but instead rely on a few key values; the magnitude of possible bad outcomes is more salient, so that there is less risk taking when greater stakes are involved; in practice, quantifying costs and benefits of a line of action is not easy (March and Shapira, 1987). Finally, the laws, rules, and administrative regulations designed to guide organizational behavior are likely to be mala prohibita rather than mala in se, thus the standards to which organizations are expected to adhere and the consequent punishments are not clear to either organization decision makers nor the public (Stinchcombe, 1965: 174-175; Calavita et al., 1997).

When the effect of the organization as a locus of choice is taken fully into account, social context becomes obvious as an influence in decision making, shaping what an individual perceives to be rational at a 
given moment. Because of specialization and division of labor, employees may be unaware of their illegality because their action was part of a chain of actions by invisible others: each individual act was legitimate, but together they constituted a violation of which some individual participants were ignorant (G ross, 1978; Finney and LeSieur 1982; Vaughan, 1983). Also, an extensive body of research and theory on decision making in organizations shows that the weighing of costs and benefits does occur, but individual choice is constrained by institutional and organizational forces: decision practices and outcomes are products of compromise, limited information, extemal contingencies, retrospective sensemaking, unacknowledged cultural beliefs, political battles, and bureaucratic pathologies that undercut both the determination of goals and their achievement (D alton, 1950; Simon, 1957; 1976; Lindblom, 1959; Allison, 1971; Zucker, 1977; March and Olsen, 1979; Weick, 1979; 1995; Feldman and March, 1981; Wildavsky, 1987; Feldman, 1989; Powell and DiMaggio, 1991). Wilensky's observation sums up the case against a de contextualized rational choice model from an organizational behavior perspective:

Too many critics of the organizational and political sources of our troubles see diabolical plots where there is only drift, a taste for reckless adventure where there is only ignorance of risks, the machinations of a power elite where there is, in William James' phrase, only a "bloomin' buzzin' confusion" (1967: vii).

This review of research and theory about decision making shows many reasons to be skeptical about prioritizing a deterrence model for the social control of organizations. In particular, the research on organizational behavior points to an altemative model of decision making demonstrating the ties between social context and rational choice. Compelling support for the influence of social contingencies in decision making comes from sociological theory articulating social life as situated action. Even more convincingly than the decision making literature, this schema suggests that a social control strategy that manipulates the consequences of choice does not go far enough.

\section{Situated Action: The Structure/ Culture/ Agency N exus}

A fundamental sociological understanding is that interaction takes place in socially organized settings. 
Rather than isolating action from its circumstances, the task of scholars is to uncover the relationship between the individual act and the social context. This argument appears in the history of sociological thought as a common thread running through the work of such otherwise diverse thinkers as Herbert Blumer, Erving G offman, Max Weber, G eorge Herbert Mead, Harold G arfinkle, G eorge Homans, and Talcott Parsons. Three recent developments allow us to build upon these understandings about the situated character of social action, showing a more complex and complete picture. These recent developments suggest that merging levels of analysis is required for a full theoretical explanation of any particular behavior; they also provide a conceptual apparatus that indicates what needs to be included in research to make full explanation possible.

The first development is the extensive theoretical literature that establishes the relationship between structure and agency. At the same time these debates ferret out the complexity of the macro-micro relationship, they lay the groundwork for research examining it (Maines, 1977; Giddens, 1979; R. Collins, 1981; Knorr-Cetina and Cicourel, 1981; Alexander et al., 1987; Fine, 1992; Sewell, 1992; Emirbayer, 1997). The second development is that culture has entered the picture as a mediating link in the structure/ agency relationship. Theorists are refining the link between an individual's position in a structure and interpretative practices, meaning, and action at the local level (Bourdieu, 1977; Hall, 1987; Smith, 1987; Harraway, 1988; P. Collins, 1990; 1991; Emirbayer and Goodwin, 1994; Hays, 1994). This nexus is identified in phenomenology as "lifeworld;" by Foucault as "episteme;" by Bourdieu as "habitus," by Smith and P. Collins as "standpoint." Although different in important ways, each perspective draws attention to culture: the tacit understandings, habits, assumptions, routines, and practices that constitute a repository of unarticulated source material from which more self-conscience thought and action emerges. Also significant is the role of history: both the historic moment, as its normative and legal standards affect individual tacit understandings, and individual history/ experience are critical to individual interpretation and meaning (Elias, 1994; Emirbayer, 1997).

Two further developments reinforce the important role of culture in situated interpretation, meaning, and action. One is the new institutionalism, which explains that organizational forms and behaviors take the form that they do because of prevailing values and beliefs that have become institutionalized to varying degrees 
(Meyer and Rowan, 1977; Zucker, 1977; Powell and DiMaggio, 1991). New institutionalists argue that cultural rules constitute actors (state, organizations, professions, and individuals), thus defining legitimate goals for them to pursue and therefore affecting action and meaning at the local level. D ecision making, from this perspective, is always rational; however, institutionalized categories of structure, thought, and action shape preferences, directing choice toward some options and not others (D ouglas, 1987; Wildavsky, 1987; DiMaggio and Powell, 1991: 10-11). The other influence is G ranovetter's (1985; 1992) work on the socially embedded character of economic action. G ranovetter points to the relative autonomy and/ or relative dependence between the forms of economic action and social organization and the institutionalized cultural belief systems within which they are located. In contrast to the new institutionalism, agency is at the heart of this analysis. Agents can be individuals or organizational forms, but the embeddedness perspective prohibits reduction to a decontextualized rational actor. Because agency is central, economic action can take a variety of forms, so in a common cultural system variations will exist that cannot be explained only in cultural terms. Together, these perspectives draw attention to the need for research that examines the structure/ culture/ agency nexus.

This complex conceptual package illuminates many aspects of situated action. D ecision making, from this perspective, cannot be disentangled from social context, which shapes preferences and therefore what an individual perceives as rational. A full theoretical explanation of the action of any social actor needs to take into account, to the greatest extent possible, its situated character: individual activity, choices, and action occur within a multilayered social context that affects interpretation and meaning at the local level. Not only the nested character of social action (Jepperson, 1991), but also the dynamic interplay between structure and agency (Fombrun, 1986; Smith, 1987; Friedland and Alford, 1991) begin to suggest the difficulty of doing empirical work that targets the situated interpretive work that precedes every social act. Moreover, doing research that encompasses all these elements requires 1) researcher expertise at studying both structure and agency, and 2) data that make a full analysis of situated action possible - two resources, often absent (Vaughan, 1992b). It is easy to understand why the theoretical debates about the relationship between structure and agency have not spawned a flurry of empirical work aimed at bridging the macro-micro gap. Instead, what is happening is that 
numerous scholars carve out a particular locus of inquiry: researchers cast their studies at either the macro- or micro-level, but not both. They take a slice of the whole, thus offering a measured but nonetheless partial view - and thus a partial explanation - of the socially organized character of group life.

Given the complexity of situated interpretation, meaning, and action, and the obvious difficulty of doing an empirical analysis of the structure/ culture/ agency nexus, one might logically ask, why bother?

\section{The Connection between Cause and Control}

To be effective, strategies for social control should target the causes of a problem. The closer we come to establishing the relationship between situated action, rational choice, and organizational misconduct, the better the understandings on which social control can be based. Research and theoretical explanations that isolate one level of analysis for attention automatically and implicitly suggest strategies for control that do not take into account relevant factors at other levels. This is not to say that isolating a particular level of analysis for research is no longer a worthy enterprise: doing so helps us flesh out the details of situated action. Y et we need to bear in mind both the practical and political implications of our work. When we restrict our analysis to the individual, social psychological, or structural level of explanation, we have isolated one element from many that comprise situated action. A partial explanation, no matter how important the finding, leads to a partial, or incomplete, strategy for social control. A de-contextualized rational choice model locates cause at the individual level of analysis, suggesting strategies for control that target responsible individuals: ethics training, punishment,

forced resignation, and so forth. While these are appropriate strategies, they are incomplete: they leave the social context untouched, tending to systematically reproduce misconduct.

Socio-legal scholars have acknowledged organizations as the locus of misconduct. Research has explored both the causes of organizational offending (Reiss, 1966; Ewick, 1981; Finney and Lesieur, 1982; Wheeler and Rothman, 1982; Braithwaite, 1984; Shapiro, 1987; Kramer, 1992; Barlow, 1993; Reed and Yeager, 1996; Punch, 1996; Abolafia, 1997; Passas, 1997) and the social control of organizations (for an excellent overview, see Edelman and Suchman, 1997). Both research and theory show that the organization and its environment have a causal relationship to misconduct. But in the absence of research that explores the 
relationship between these structural factors and decisions to violate, gaps in knowledge remain that may have serious implications for the social control of organizations. Case studies in naturalistic settings (Manning, 1986) can explore decisions to engage in organizational offenses as situated action, but to date the opportunity to do so has been infrequent.

The 1986 Challenger tragedy produced data that opened up the structure/ culture/ agency nexus (Vaughan, 1996). My data were personal interviews, government investigation reports and hearing transcripts, publications by historians, scientists, engineers, and journalists, plus over two hundred thousand original NASA and contractor documents, assembled by the Presidential Commission investigating the disaster and stored at the National Archives, Washington D.C.. The latter included over 9,000 pages of legal deposition transcripts, documentation of NASA rules and procedures, engineering reports, risk assessments, correspondence and memos, safety panel reports, daily engineering activity sheets, pre-launch decision making records, and computerized problem tracking system print-outs. These resources allowed me to make a chronological reconstruction of the history of decision making about the Solid Rocket Boosters, the technical cause of the accident, at NASA from 1977 through the Challenger launch. The result is an historical ethnography of decision making in a naturalistic setting that situates decisions within the structures and processes that shaped interpretive work, preference formation, and choice.

D ue to space limitations, the summary that follows omits the ethnographic thick description in the original that shows the negotiation of meaning, its contested character, and how shared cultural understandings can co-exist alongside differences and unsettled disputes. Lost, too, is the role played by coincidence,

disorganization, fumbling, and just plain not knowing. Also, only a few citations to key ideas are included. The purpose is to present, in broad strokes, the grounded theory of decision making at NASA in order to sensitize

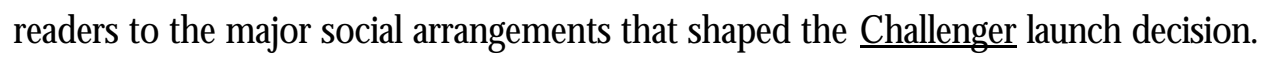

\section{H ow Deviance Became Nomal: The Challenger Case}

In the aftermath of the tragedy, the historically accepted explanation of the controversial 1986 Challenger launch decision conformed to the amoral calculator model. Warned by contractor engineers that 
launching was risky in the unprecedented cold temperatures that were predicted at launch time, NASA managers nonetheless proceeded with the launch because the schedule had become all-important at the space agency. Underfunded by Congress, the Space Shuttle program depended upon income from commercial satellite companies: the greater the number of flights per year, the greater the number of commercial payloads, the greater the income. Realizing the importance of schedule (the historically accepted explanation went), the managers who were immediately responsible for the decision responded to these pressures by disregarding the advice of their own engineers, knowingly violating rules about passing safety concerns up the hierarchy in the process. Seven astronauts, including Christa McAuliffe, Teacher-in-Space, lost their lives. The conjunction of competitive pressures, scarce resources, rule violations, and overriding the objections of engineers suggested intent: managerial decision making as violative behavior - a calculated, amoral, consequentialist, rational choice.

Production pressure played a critical role in the fatal decision, but the historically accepted explanation

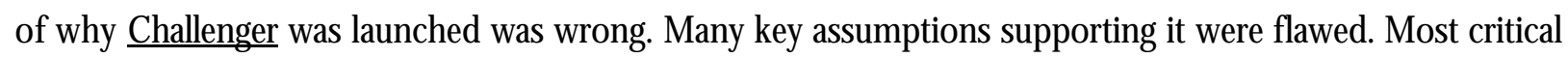
for establishing the intent implicit in an amoral calculator explanation, NASA documents describing rules and procedures showed that managerial actions identified as rule violations by the Presidential Commission were in fact actions that conformed to NASA rules. Because no rules were violated, the case does not conform to traditional understandings of organizational misconduct that have employees violating laws and rules in pursuit of organization goals, nor does it exhibit the intent to do wrong implied in the amoral calculator model of decision making. However, something more insidious went on that may also be a pre-condition of illegality. The case shows that in the years preceding the Challenger launch, engineers and managers together developed a definition of the situation that allowed them to carry on as if nothing were wrong when they continually faced evidence that something was wrong. This is the problem of the normalization of deviance.

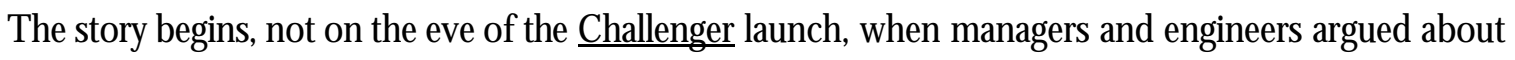
whether to go forward or not, but nearly ten years earlier. The past - previous engineering analysis, conclusions, and launch decisions - was an all-important context for decision making on the eve of the launch. Prior to the Challenger launch, the Solid Rocket Boosters (SRBs) frequently incurred damage on shuttle missions. After each 
incident, the work group recommended to their superiors to accept risk and fly. After the disaster, continuing to launch despite evidence of damage on many flights seemed not only deviant but an amoral, calculated choice to a public shocked by the death of the astronauts. Why didn't they stop launching until they had solved the problem? Because at the time decisions were being made, each technical anomaly was first defined as an escalated risk; then, after engineering analysis, it was redefined as normal and acceptable by decision makers. Three factors, in combination, explain the normalization of deviance: the production of a cultural belief system in the work group, the culture of production, and structural secrecy.

\section{The Production of Culture.}

Risk assessment was a bottom-up process at NASA. The managers and engineers assigned to do the technical work on Space Shuttle component parts assessed risk daily, using NASA guidelines and relying on engineering tests, post-flight analyses, and calculations. Then, in a formal pre-launch decision process known as Flight Readiness Review, these work groups presented their risk assessments and recommendations about launching to superiors in what was a multi-layered, multi-participant, adversarial review process. Because the shuttle design had no precedent, risk was always negotiated and often controversial. But in order to launch shuttles, work groups had to assay each technical component and find it an "Acceptable Risk," following prescribed NASA and engineering methods. Arriving at this official designation had them routinely converting technical uncertainty into certainty.

Culture can be thought of as a set of solutions produced by a group of people as they interact about the situations they face in common. These solutions become institutionalized, remembered and passed on as the rules, rituals, and values of the group (Van Maanen and Barley, 1985). As the Solid Rocket Booster work group interacted about their task, their interpretive work became the basis for an official definition of the boosters as an "Acceptable Risk." The SRB work group's definition of the situation became an institutionalized cultural belief. To understand how this cultural belief originated and continued as returning flights showed continual signs of booster damage, we start with micro-level influences on decision making. Two were important: social context and patterns of information. They affected the interpretive work of the work group, so that what 
appeared to the public in the aftermath of January 28, 1986 as clear and undeniable signals of danger were interpreted as weak signals, mixed signals, or routine signals by the engineers making risk assessments as the decisions were being made.

The immediate social context was one in which having problems was normal and expected because 1) the design was unprecedented and therefore untested in flight, and 2) the shuttle was designed to be reusable. Consequently, having booster anomalies was not deviant because engineers and managers expected that all returning flights would have some damage that had to be fixed prior to the next launch. Patterns of information as boosters were inspected after each mission also affected the definition of the situation. Most launches had no booster anomalies. When they occurred, they seemed to be random. Post-flight engineering analysis indicated these technical deviations were shaped by "local conditions": peculiarities that were non-systemic in origin. Each time, engineers were able to identify the cause of the failure and fix it, assuring themselves by tests, calculations, and scientific methods that the problem was within the bounds of acceptable risk. Subsequent missions would have no anomalies. Then a new incident would occur.

The pre-existing definition of the situation, and the scientific procedures and engineering analysis on which it was based, became the context against which the risk of each succeeding anomaly was measured. Each incident was assessed in light of a gradually developed engineering analysis about conditions that might occur and the boosters' ability to tolerate those conditions. The incremental character of damage also had a normalizing effect. Had all the changes occurred at once, had damage been occurring on every flight due to a common cause, or had there been a discernable pattern of damage, the work group would have had some strong, clear signals with the potential to challenge the cultural belief in risk acceptability. Instead, the damage occurred incrementally, each incident's significance muted by social context and a learning by doing approach that had engineers interpreting each episode as separate and local.

The immediate social context and patterns of information explain how the cultural belief in acceptable risk developed. But why did their official definition of the situation persist, in the face of evidence of continuing problems? This is the problem of cultural persistence. Macro-level factors - the culture of production and 
structural secrecy - contributed to and affirmed the work group's belief in acceptable risk prior to $\underline{\text { Challenger. }}$ The Culture of Production.

The culture of production reinforced and maintained the work group's belief in acceptable risk because their actions conformed to its mandates. Thus, they saw continuing to launch under the conditions they faced as normative and conforming, not deviant. By culture of production, I mean institutionalized cultural belief systems that shaped interpretation, meaning, and action at the local level (Van Maanen and Barley, 1985; Zucker, 1977). These cultural meaning systems affect choice by functioning as institutionalized scripts that convey to people what is normal and acceptable in particular situations. In contrast to the historically accepted explanation that depicted a unidimensional NASA culture dominated by production concerns, the culture of production incorporated three cultural imperatives: the original technical culture of excellence created during the Apollo era (methodological rigor and quantitative science), political accountability (production and cost concerns), and bureaucratic accountability (attention to rules and procedures). Production pressure does not lose salience in this revisionist account, but gains importance because of its seductive influence: production pressures affected the choices of managers and engineers alike, by affecting decision making at a prerational level.

The culture of production existed outside the work group's daily negotiation of risk but had a layered, or nested, character that permeated their risk assessment processes (Jepperson, 1991). It originated in institutionalized cultural beliefs of the engineering profession that were elaborated in distinctive ways in the NASA organization, permeating Marshall Space Flight Center at Huntsville, Alabama, home of the Solid Rocket Booster Project. Of the cultural belief systems that typify engineering as a profession, three were influential in work group decision making. First, in the engineering of unprecedented large scale technical systems, uncertainty, learning by experience, and developing ad hoc rules to guide technical decisions are taken-for-granted understandings about how work gets done (Wynne, 1988). Second, "satisficing," not "optimizing," was normal and acceptable in the engineering profession (Simon, 1957; 1976). The education of engineers prepares them to work in production systems where technology is product-oriented and cost/ safety trade-offs are routine, so satisficing on design is common and non-deviant (Petroski, 1985; Meiksins, 1988; Kunda, 1992). Third, technical 
assessments are grounded in "trust in numbers" and "trust in rules:" quantitative methods and scientific objectivity in risk assessment hold sway over intuitive sensibilities (Jasanoff, 1986; Porter, 1995); engineers are trained to work in hierarchical organizations where rule following is associated with safety (Meiksins, 1988; Petroski, 1985).

These institutionalized beliefs of the engineering profession materialized in the NASA organization in distinctive ways that contributed to the normalization of technical deviation on the SRBs. During the Apollo program of the '60s, NASA's original technical culture was founded on a mandate for technical excellence (McCurdy 1993). The emphasis was on the "dirty hands" approach: contractors were only used occasionally, and most work was done "in-house" so that top administrators and technicians alike got their hands "dirty" by staying in close touch with the technology. This approach was joined by a near-obsessive emphasis on technical excellence, scientific positivism, and rigor in both method and data analysis. However, at the inception of the shuttle program in the '70s, NASA's purist technical culture was joined by an additional cultural mandate: political accountability that called for attention to cost and schedule (Romzek and Dubnick, 1987). As the Apollo program neared its end, consensus for the US space program was undermined by the US involvement in Viet Nam. The war created a drain on the budget, raising questions about continued space explorations.

NASA administrators developed the Space Shuttle Program as the post-Apollo goal. Confronted by Congressional recalcitrance and opposition, agency administrators proposed that the shuttle would not be a drain on the budget because it would be, to a great extent, self-funding. NASA officials pushed the vehicle as a reusable "space bus" that could fly many missions a year. Designed with a large payload bay, the shuttle would carry experiments from aerospace R\&D firms and commercial satellites to be put in orbit, thus collecting money for each mission. When the proposal went to Congress, the projected number of missions assured a continued source of income from a space vehicle that administrators insisted would make space flight "routine and economical." The shuttle was endorsed on this basis. Reduced funding had converted the R\&D space agency into one that operated like a business, complete with production cycles and concerns about cost and efficiency. 
A second alteration in NASA culture that occurred was that bureaucratic accountability ascended in importance (Romzek and D ubnick, 1987). Bureaucratic accountability had always been esteemed: rules were essential for coordinating work and for safety. However, in the 1980s, the agency became bureaupathological. Contracting out, formerly an occasional practice, became institutionalized. The consequence was that an immense new rule structure was necessary to coordinate NASA/ contractor relations. The dirty hands approach was compromised: many NASA engineers and technicians now had contractor oversight responsibilities, so were burdened with procedural tasks and huge amounts of paperwork. Soon after shuttle missions began in 1981, still another layer of bureaucracy was added. The 1980s were notable for the decreased regulation of business and the increased regulation of government agencies, which imposed another system of accountability on the space agency. The result of these changes was that rule-following and procedural conformity rivaled the original technical culture and political accountability. History and politics had not eliminated the original technical culture of the Apollo era, but added political accountability and bureaucratic accountability to it. The result was that engineers and managers assigned to the shuttle hardware were struggling to conform to the mandates of the original technical culture while also conforming to political accountability (cost and schedule) and bureaucratic accountability (procedural requirements).

The Macro-Micro Connection. The work group conformed to the culture of production, which had an impact on cognition. It contributed to the normalization of technical deviation of the SRBs as follows. Post-flight analyses of the Space Shuttle missions produced quantitative evidence (the original technical culture) convincing the work group that the booster design was an acceptable risk. Although they understood that the boosters were working, they did not understand why they were working as they were. G rowing doubt, uncertainty, and concern about the unknown notwithstanding, concern about cost and schedule (political accountability) inhibited the work group from halting missions for the lengthy period necessary for additional tests. Following the rules, which they unfailingly did (bureaucratic accountability), had a social psychological effect. Conforming to every rule and procedure - going by the book - assured them that their official risk assessments were correct, sustaining the cultural belief that the design was an acceptable risk. As the problem 


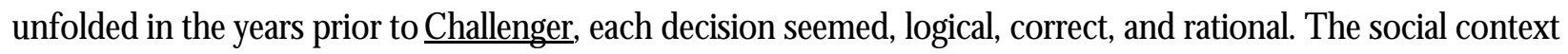
and patterns of information that affected the definition of the situation were reinforced by the institutionalized cultural frame within which the interpretive work was done.

\section{Structural Secrecy.}

Because the process of deviance normalization went on from 1977 until the fatal Challenger launch, we must wonder why no one outside the work group noticed and acted. Structural secrecy was the third factor that contributed to the persistence of the work group's cultural belief in acceptable risk. The effect of structural secrecy was to inhibit people outside the work group from overturning the definition of the situation. Structural secrecy refers to the way that the structure of organizations and their regulatory relations impedes knowledge and understanding of activities in the workplace. In the aftermath of the Challenger tragedy, managers were wrongly accused of individual secrecy: intentionally violating rules to hide information about booster problems

from others in the organization. No rule violations occurred. Instead, it was routine characteristics of inter- and intra-organizational relationships - conditions common to all organizations - that concealed the seriousness of the technical problem on the Solid Rocket Boosters from people outside the work group, preventing them from identifying the trend and intervening in some way that might have altered the decision making pattern prior to the $\underline{\text { Challenger launch decision. }}$

Secrecy is built into the very structure of organizations. As organizations grow large, actions that occur in one part of the organization are, for the most part, not observable in others. Division of labor between subunits, hierarchy, and geographic dispersion segregate knowledge about tasks and goals (Lazega, 1992). Distance - both physical and social - interferes with the efforts of those at the top to "know" the behavior of others in the organization - and vice-versa. Specialized knowledge further inhibits knowing. The language associated with a different task, even in the same organization, can conceal rather than reveal. Changing technology also interferes with knowing, for assessing information requires keeping pace with these changes a difficult prospect when it takes time away from one's primary job responsibilities. Also - and ironically - rules created to communicate more information can result in knowing less. Rules that guarantee wide distribution of 
information can increase the paperwork on individual desks so that a lot is not read. Executive summaries, although effectively conveying major points, condense and omit information, selectively concealing and revealing.

Paradoxically, NASA had developed both a pre-launch decision making procedure and a safety regulatory system designed to protect against structural secrecy. The formal, hierarchical, pre-launch decision chain known as Flight Readiness Review (FRR) was designed to maximize information exchange by pulling all parts of the organization together for risk assessments prior to a launch. All engineering risk assessments were distributed in advance and orally presented in FRR, where they were critiqued aggressively by people outside the work groups whose sole responsibility was to uncover flaws in the analyses. Moreover, NASA had both internal and external safety review panels designated as safety regulatory agencies with oversight responsibilities in every aspect of technical work. However, structural secrecy remained (Vaughan, 1990). While structural secrecy had many unanticipated negative consequences for safety, here I will isolate only one: information dependencies and how they kept people outside the work group from identifying the pattern of normalizing technical deviation and intervening.

In NASA 's bottom-up risk assessment system, it was the work groups' construction of risk - and the engineering evidence supporting their assessments - that were the basis for all launch decisions. FRR and safety regulatory systems were designed to challenge and oversee existing risk assessments and the scientific procedures and technical knowledge that went into work group launch recommendations. But the shuttle was made up of 60 million component parts. FRR participants and regulators were inundated with information about each part. Instead of enlightening upper level managers, the deluge of information obfuscated many problems (Feldman and March, 1981). Hence, people with oversight responsibility relied on oral interpretation and briefings in FRR and other inquiries. Removed from the hands-on work and reliant on work groups for the engineering on which risk assessments were based, these others could only challenge what was presented to them. When the SRB work group repeatedly defended their position with quantitative data, as those assigned to the Solid Rocket Booster Project did in the years preceding the Challenger tragedy, top NASA administrators 
and safety officials became persuaded the design was an acceptable risk. The work group's construction of risk was affirmed up the hierarchy, becoming the official organizational construction of risk prior to each launch.

NASA's oversight structure functioned effectively as a review system, but information dependencies interfered with its ability to identify basic assumptions that were in error. The House Committee on Science and Technology, whose investigation followed that of the Presidential Commission, concluded that administrators and regulators only knew what work groups told them:

Flight Readiness Reviews are not intended to replace engineering analysis, and therefore, they cannot be expected to prevent a flight because of a design flaw that Project management (read: the SRB work group) had already determined represented an acceptable risk...(U.S. House, Committee on Science and Technology, 1986: 148; 70-71).

Thus, the official definition of the boosters as an acceptable risk persisted through the end of 1985. Challenger was the first launch of 1986. The decision to launch $\underline{\text { Challenger }}$ was one decision in a stream of decisions about the boosters. The debate that night was situated in history and social organization: the interplay of the production of culture in the work group, the culture of production, and structural secrecy affected the interpretative work and action of all participants.

\section{The Eve of the Launch}

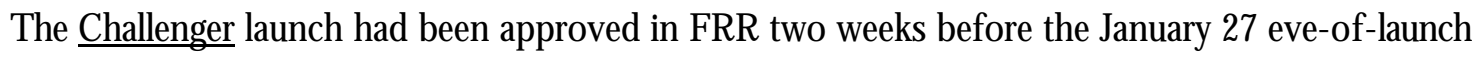
discussion. But this was an emergency meeting, called because the temperature forecast resulted in a revised assessment of risk acceptability for the boosters before launch the next morning. So the 34 participants, located at agency and contractor facilities in Utah, Alabama, and Florida, held the discussion on a teleconference. It was unprecedented in several ways: the predicted cold temperature, the no-launch recommendation that the

contractor engineers made, and the geographic locations of the participants. The purpose of the teleconference was to weigh the new circumstances to determine whether or not the engineering rationale for flight they had developed in preceding years was threatened by the cold. History mattered. All who were present that night were assessing new information within an historic and official definition of the situation: the production of 
scientific/ technical knowledge in the work group that supported accepting the risk of previous flights. Second, the interaction took place within the same culture of production that had systematically contributed to the normalization of anomalous incidents in the past. The original technical culture, political accountability, and bureaucratic accountability affected the discussion, shaping the construction of risk on which the Challenger launch decision was based. Finally, although a relatively small number of people participated, they reproduced the specialization, hierarchy, and geographic distribution of the larger NASA/ contractor structure. So it is not surprising that structural secrecy inhibited the proceedings that night as it had before, creating obstacles to information exchange, knowledge, and understanding.

NASA's cultural mandate for political accountability undermined the proceedings at the outset. Contractor engineers in Utah, aware of deadlines and cost concerns, immediately set a deadline for their preparations so the teleconference might begin and a decision reached before midnight, when time consuming and expensive pre-launch procedures would begin at the launch site at Cape Kennedy, Florida. Rushing to meet their own deadline, contractor engineers divided up responsibility for the charts of engineering analysis, faxing them to other places without collectively assessing them. The result? NASA managers identified errors in the charts that contradicted the argument contractor engineers were making, so the analysis did not live up to the rigorous quantitative standards of NASA's original technical culture. Political accountability showed itself a second time when NASA managers, surprised that a flawed engineering analysis would be the basis for a no-launch decision when schedule was so important, gave their usual adversarial challenges in unusually harsh ways, intimidating contractor engineers and managers.

Throughout the discussion, structural secrecy blocked understanding. Engineering launch recommendations were always face-to-face in FRR. However, this night the participants were in three facilities of the NASA/ contractor structure, an unreflexive choice that went unquestioned because teleconferences had become a normal way of doing business between contractors and NASA. In separate locations, with no video hook-up, words and inflections had to convey everything. Body language, facial expression, who was present or absent - additional information that adds to interpretive abilities and conveying meaning - were unavailable. 
At a critical moment, the effect of structural secrecy was increased when the contractor representatives went off the teleconference line for a caucus. D uring that period, contractor administrators reversed their own engineers' recommendation. They returned to the teleconference with a recommendation to accept risk and fly. Separated by distance and a mute button, no one at the other two locations knew that the contractor engineers still objected. Further, the contractor engineers were unaware that people in the other two locations were expecting the launch to be stopped.

The cultural mandate of bureaucratic accountability had people going by the book, which also had a deleterious affect on the discussion. First, conformity to normative expectations about specialized knowledge and hierarchical relations affected talk: some people were silent who had information that might have altered the outcome. Some deferred to authority; others, concluding that they had not worked on the booster problems recently enough or were insufficiently informed for other reasons, kept their insights to themselves, deferring to the few engineers presenting the analysis. Second, in unprecedented conditions, all participants followed all the usual NASA rules and procedures about how launch decisions were to be made. As in the past, conforming to rules had the latent social psychological effect of affirming the correctness of the decision: all contractor engineers but one left the teleconference believing that the boosters would incur addition damage, not expecting a catastrophe. The one person who did fear the worst said nothing on the teleconference, abiding by NASA's bureaucratic norms about who legitimately could speak during an engineering decision and under what circumstances.

But conformity had a still greater consequence. Immediately following the disaster, many of the participating engineers admitted their analysis was flawed, stating that "we didn't have the data to convince NASA," so the pre-existing engineering analysis that supported acceptable risk stood. However, retrospection

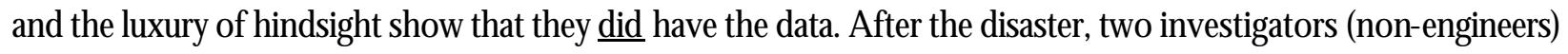
working for the Presidential Commission did a trend analysis of all launches, examining the relationship between temperature and booster damage. The quantitative data conclusively proved the correlation between cold temperature and damage (Vaughan, 1996: 382-383). But the work group did not create that chart, which would 
have conformed to the positivistic mandates of the original technical culture, thereby stopping the launch. Customarily, in conditions of uncertainty, people fall back on habits and routines (Mileti et al., 1985). In unprecedented circumstances, with time to think things through, the engineers and managers in the work group followed all the mandates of the culture of production. No one had the idea to proceed in a different way.

Consider this. Whereas a rigorous, quantitative engineering analysis may assure safety in a pro-launch decision, in a no-launch decision under unprecedented, uncertain launch conditions, accepting qualitative observations and intuitive insight from technical experts closest to the technology would have been appropriate. Whereas hierarchical, adversarial FRR discussion style is suitable for pro-launch recommendations, a democratic sleeves-rolled-up-let's-all-put-our-heads-together-to-see-what-we-can-make-of-these-data strategy would have been a logical response. Again, we have the luxury of hindsight. The situation looked very different to them at the time. The work group conformed to the triumvirate of cultural imperatives, resulting in an official decision that incorporated yet another anomalous condition, thus extending the bounds of acceptable risk a final time.

\section{On the Social Control of Organizations}

Gordon writes, "That life is complicated may seem a banal expression of the obvious, but it is nonetheless a profound theoretical statement - perhaps the most important theoretical statement of our time (1997: 3)." To reduce what happened at NASA to a subjective-expected utility model is to strip away the complexity that explains the tragedy. The above summary shows some of that complexity, but does injustice to the complexity of the original analysis, which, in turn, does injustice to the complexity of the incident. What nonetheless remains capturable is the relationship between situated action and rational choice. Rational choice theorists are the first to admit that the power and scope of rational choice theory is limited because insufficient progress has been made toward a theory of preference formation (Friedman and Hechter, 1988: 214; Hechter and Kanazawa, 1997: 208). Such a theory must rest on an understanding of the definition of the situation actors

hold when choices are made. This case demonstrates that individual choice cannot be understood by isolating it from its organizational context, and neither can the organization be isolated from the external environment. 
The work group's production of a cultural belief about booster risk, the culture of production, and structural secrecy were seductive shapers of preferences and interests during the teleconference and the years preceding it. And so was history. D ecision making was greatly influenced by precedent, in contrast to most macroscopic sociological rational choice theories, which assume that actors are forward-looking maximizers (Hechter and Kanazawa, 1997: 209).

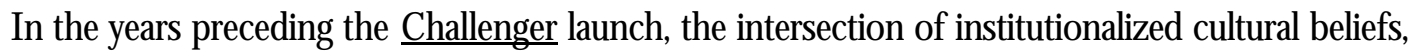
organization structure and culture affected cognition: the work group created a frame of reference through which booster performance was assessed. It became institutionalized, shaping interpretive practices so that decision makers viewed their actions as conforming, not deviant, as outsiders - and the decision makers themselves - viewed these same actions after the disaster. They imagined benefits, not costs, as a result of their decisions. The eve-of-launch teleconference was called because conditions changed: many engineers felt that launching would bring only costs. But in the process of assessing risk, the interpretation, meaning, and actions of participants were shaped by the same social factors that affected previous decisions: the pre-existing definition of booster risk remained the work group's official position. Each and every launch recommendation was a rational choice, made rational by the situated character of social action, which narrowed the options and influenced the choices decision makers saw as rational at the time. Preference formation looms large in this schema. In contrast, the amoral calculator model brackets individual choice from social location, history, and pre-existing definitions of the situation, emphasizing the calculation of future consequences at the expense of the pre-conditions of choice.

NASA made a decision that caused extensive social harm, but absent was any evidence of intent to do that harm, or the calculated, knowing violation of rules or ethical or normative standards that are essential to the amoral calculator model of organizational misconduct. This was true not only for the SRB work group, but also for political elites inside and outside the space agency: top NASA officials, Congress, and the Administration. These powerful elites set up the tragedy in the years preceding Challenger by making political bargains that 1) made routine and economic space flight a priority, thereby interjecting production pressures into the culture and 
affecting risk assessments by working engineers, and 2) allowed civilians to fly on the shuttle to promote the agency and its goals. Missing from the original media-generated, historically accepted explanation of amorally calculating managers were the invisible workings of power and politics that contributed to the outcome. At the time they were made, these elite decisions, too, were absent intent to do harm or violate laws, defined as normal and acceptable by the top officials who made them.

Although no rules were violated in launch decision making about the Solid Rocket Boosters, it is possible that the processes of deviance normalization revealed in this case may play a role in facilitating rule violations and misconduct when they do occur in other organizations. The usual disclaimers about generalizing from a case study notwithstanding, this conclusion not only has strong support from socio-legal theory that links culture to organizational misconduct (see Vaughan, 1997; 1998), but also from other research that contextualizes decisions to violate. This research is not extensive, nor was it designed specifically to target decision making in naturalistic settings, so it does not attempt to explore all possible aspects of situated action. But it does 1) support the normalization of deviance as a generic social process at work when rules and regulations are violated in occupations, industries, and a variety of organizations, and 2) affirms the role of culture in deviance normalization. Typically, culture is not named in this research; instead, its explanatory power is expressed in the concepts norms and normative environment.

The basis for research connecting culture with the normalization of deviance was laid by Sutherland (1949), who theorized that crime is learned in interaction in primary groups and will occur when individuals develop "definitions favorable to violation" that exceed "definitions unfavorable to violation." The first to tap into culture empirically was Quinney (1963), who compared occupational norms of pharmacists, finding that those who were oriented toward business norms were more likely to violate than those who were oriented toward professional norms (see also Greene, 1997). Q uinney's research design did not allow him to examine pharmacists' decisions to violate, but the few case studies have been revealing. In the heavy electrical equipment conspiracy case, G eis (1967) was able to make a breakthrough. Although socio-legal scholars traditionally have interpreted the premeditation and collusion of Geis's conspirators as evidence of amoral calculation, his data 
suggest that the normalization of deviance may have affected their decisions. G eis found the responsible executives were conforming to industry norms, so in their view, their actions were not deviant - even though they knew them to be illegal. The Ford Pinto case study, often cited to support amoral calculation, also suggests that an internal normative environment developed where deviance became normalized within the organization.i. Three important books, originating in other disciplines, argue that individuals committing heinous crimes against individuals and humanity defined their own actions by the cultural standards of organizations - political parties, nation states, the military - thus, they saw their actions as conforming, not deviant: Arendt's Eichmann in Jerusalem (1964); Kelman and Hamilton's Crimes of O bedience (1989), and most recently, Goldhagen's controversial and hotly disputed Hitler's Willing Executioners (1996). All three show how power, politics, and elites created cultures that normalized deviant actions. When discovered, a horrified world defined these actions deviant, yet they were normative within the culture of the work and occupations of the participants who acted in conformity with organizational mandates.

The lesson suggested by the Challenger case and these others is that the legal and regulatory apparatus might better investigate and elevate the importance of additional strategies of social control. The potential deterrent impact of sanctions cannot figure into individual calculations when history, culture, and structure congeal in a world view such that behavior that is objectively deviant to outsiders is normal and legitimate within a particular social context. When deviance becomes normalized, individuals see their actions as conforming, not deviant; consequently, they see their actions as accruing benefits, not costs. By definition, the potential deterrent impact of negative sanctions is mitigated by the situated character of social action. Punishment is appropriate; people must be held responsible for action resulting in social harm. It may be used against offending organizations and/ or their employees to accomplish other than deterrence: to make people publicly accountable for their actions, to assure restitution or retribution, for example (Schlegel, 1990). However, as a strategy of social control punishment does not go far enough. It de-contextualizes decisions to violate, neglecting the social context that leads people to make the choices that they do. The organization may be fined; the responsible individuals may be incarcerated, fined, fired, transferred, or offered early retirement, but if the 
social context of decision making is not altered, the next position incumbent's decision making will be subject to the same organizational contingencies. Without attention to these other factors, the legal and administrative apparatus - and the public - are wrongly persuaded that once the responsible person is punished, the problem is solved. But the more-difficult-to-diagnose goals, policies, cultures, and structures that create definitions favorable to harmful social acts remain unchanged, perpetuating the possibility of recurrence.

A punitive strategy needs to be augmented with a new approach that calls for institutional reform. Alternatives to punishment exist, and these alternatives should be developed and continued (see, e.g., Bardach and Kagan, 1982; Braithwaite, 1985; 1989; Grabosky and Braithwaite, 1986; Ayres and Braithwaite, 1992; Fisse and Braithwaite, 1993). However, most alternatives do not target those goals, cultures, and structures that constitute the social location of decisions to violate. Within a situated action paradigm, what kinds of strategies for control might be appropriate? Solutions would need to be tailored to the problem (e.g., environmental pollution, price-fixing, NCAA recruiting violations; complex organizations; small businesses; non-profits), but violative behavior across organizations has many generic aspects. Among them are competition for scarce resources and structural secrecy, which had major implications for what happened at NASA. With the details of the Challenger case fresh in mind, we will imagine some generic strategies that connect cause with control. These call for legally mandated intrusions on the inner, traditionally private, organizational domain.

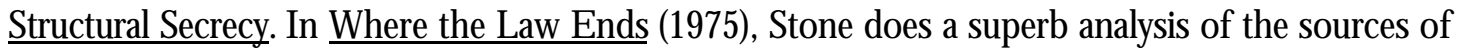
structural secrecy and suggests a comprehensive approach for opening up the visibility and accountability of employees at all levels, while still being sensitive to the needs for organizational autonomy. G rounded in a lawyer's understanding of the potential of the law, Stone proposed that regulators mandate changes in the configurations of internal decision structures and processes that alter authority lines and information flows. Among his proposals are altering the composition, responsibilities, authority, and function of Boards of Directors and creating General and Special Public Directorships (1975: 122-183). He recommends using consent decrees to "mend the information net" by imposing appropriate information systems as part of a settlement package (1975: 199-216). These would include information handling standards, installing 
government inspectors, detailed internal reporting systems, and facilitating and protecting whistleblowers. Contending that the emphasis should not be on what organizations are deciding but on how they are deciding it, he draws on legal precedent to show how responsibility can be reallocated and accountability mandated (1975: 217-227).

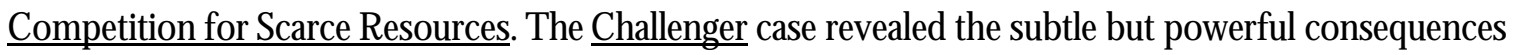
of executive policies: in response to competitive pressures and scarce resources, top NASA administrators made decisions that altered the culture and structure of the organization, ultimately shaping the options that engineers saw as rational when assessing risk. Research repeatedly affirms that goals set by top administrators in response to competitive pressures result in pressures to violate in the middle and lower reaches of the hierarchy (see, e.g., Clinard, 1983; Jackall, 1988; Calavita et al., 1997). G oals geared toward increased productivity and profits are chief among them, as are related decisions intended to cut costs. For example, downsizing cuts costs by reducing the number of employees. If service or production goals remain the same, production pressures on remaining employees will increase, thereby increasing the probability of violations. Ironically, punitive or restitutive fines imposed by regulators (or other sanctions that reduce status or the ability to compete) increase competitive pressures on an organization. Regulators could hold top administrators accountable for the acts of their subordinates, even when there is no "smoking gun," by mandating top administrators to bring organization goals into harmony with available resources. By reducing production pressures, an aspect of organization culture is altered that is incontrovertibly associated with violative behavior.

Expanded use of a compliance strategy of social control would address both structural secrecy and the effect of production pressures on internal culture. In contrast to a legalistic deterrence approach, a compliance strategy is designed to prevent violations from occurring because the social harm that can result from violation may be so extensive that punishing after the harm is done is an undesirable option (Hawkins, 1984; Reiss, 1984; Braithwaite, 1985). Compliance is the strategy of choice in industries and organizations that use hazardous materials and risky technologies, but could be used regardless of the task or product. Compliance to laws and rules is negotiated by regulators who make frequent site visits to maintain adherence to regulatory standards. 
Sanctions are available but seldom imposed, the threat providing leverage to persuade managers and workers to comply. By having a regulator often on-site, a compliance strategy opens up structural secrecy; also regulators who are not seduced by the culture bring fresh eyes to the workplace. While there is much that outsiders do not see, they may see what insiders take for granted and don't see. Also, they are empowered to interject contradictory signals - warnings, sanctions - that challenge developed cultural understandings. For some employees, frequent visits by a regulator may be incentive for more carefully concealed deviance; for others, the presence of regulatory authority may be a reminder of alternative normative standards.

These examples (and others) need to be debated and considered more deeply than is possible here, but they still show that it is possible to tie existing strategies for control to the relevant social conditions surrounding choice. The problem is that so cio-legal scholars remain poorly informed about what drives decisions to engage in organizational misconduct, and as long we are poorly informed, regulatory policy will be governed by existing assumptions instead of the results of research. Undoubtedly, amoral calculation explains many incidents. However, the Challenger case provides an alternative model. It raises the possibility that what often appears to be purely consequentialist amoral calculation - Michael Milken, the Savings and Loan debacle - may be significantly shaped by pre-conditions of choice that normalize deviance. Rather than acting illegally, then invoking techniques of neutralization to minimize their experience of guilt and culpability (Sykes and Matza, 1957), many offenders may never define their behavior as wrong in the first place. Moreover, other possible decision models exist that research has not begun to explore (Kagan and Scholtz, 1984). Because causal explanations have important implications for social control, a socio-legal research agenda might logically attempt to get a better understanding of situated action, decisions to violate, and organizational misconduct.

\section{Situated Action and Rational Choice: A Research Agenda}

To fully capture the structure/ culture/ agency link in situated action, case studies in naturalistic settings offer the greatest potential. The cases do not need to be sensational incidents that produce massive amounts of data, as the Challenger tragedy did (see also Allison, 1971), but could focus on small organizations, both public and private (see, e.g., G rabosky, 1989; Barlow, 1993). Case studies and ethnographies expose the greatest 
number of structures and processes (Ragin, 1994). Many of the organizational and institutional forces that affected decision making at NASA were invisible to participants; thus, any research strategy that only relies on interview data may be handicapped because interviewees may not be able to articulate many of the factors that affected their actions. Also, when organizations keep records of decisions, as NASA did, case analyses can circumvent the limits of retrospection: research can investigate how meanings are constructed and how decisions result $\underline{\underline{n}} \underline{\text { situ }}$ at the time they are made, rather than relying heavily on interviews that reflect retrospective reconstruction of events. What matters most is that the research is designed to explore systematically how the known correlates of organizational misconduct - the competitive environment, organization characteristics, and the regulatory environment, in combination - affect decisions to violate. Because case studies 1) more fully reveal the relationship between situated action and rational choice, and 2) use an inductive approach, they can expose the conditions of both amoral calculation and the normalization of deviance, as well as alternative explanations of decisions to violate.

Here are some directions this research agenda might take:

1. The most important target is the unexplored empirical boundary about the relationship between structure and agency. We have data on structure; we have data on agency; but we have little tracing the empirical link between the two. By definition, exploring the structure/ agency relationship requires examining culture, which mediates between structure and agency. In an important essay, DiMaggio (1994) reviews and analyzes an extensive literature showing the connection between culture and economy. He emphasizes that culture constitutes economic action, just as it constitutes other logics. Culture constitutes the normative regulation of exchange, the institutional basis of markets, extra- and intra-organizational environments, and the framing and multiple logics of action - all known to be relevant to explaining organizational misconduct. Culture also has achieved taken-for-granted status as an explanatory variable in the sociology of complex organizations. The relationship between culture and cognition also has been established (DiMaggio, 1997; Zerubavel, 1997). We already have some quite interesting research that sheds light on culture and organizational illegality (e.g., Clinard, 1983; Jackall, 1988; Barlow, 1993; Morrill et al., 1997), but the available data have not been analytically 
interpreted as "culture," nor have attempts been made to link that data systematically to decisions to violate. An important research challenge is to identify the connection between cultural beliefs - embedded in state, industry, professions, and organizations - and decisions to violate. New research in organizations that is specifically designed to examine culture beliefs and the symbolic meaning of law, patterned after the work of Ewick and Silbey (1998), would be essential to this agenda.

2. Socio-legal research might include taking advantage of theory and research in other literatures that could lend fresh insight into situated action and decision making in organizational offending. Within sociology, the literature on, for example, network analysis, social psychology, economic sociology, cultural sociology, and organization theory are rich in research and concepts that could be useful analytic tools. Moreover, cultural anthropology, industrial relations, cognitive psychology, organization theory, and administrative science and management have numerous alternative decision making models that contextualize decision making, but these models have received insufficient attention from socio-legal scholars (see, e.g., Simon, 1957; March and Simon, 1958; Allison, 1971; Weick, 1979; 1995; Kahneman, Slovic, and Tversky, 1982; Heimer, 1988; DiMaggio, 1997). Collaborative interdisciplinary research could be productive, combining specialists who have different expertise: e.g. an anthropologist, organization theorist, or cultural psychologist in combination with law, sociology of law, or criminology.

3. Comparative case research is another undeveloped avenue. Case comparisons would illuminate similarities and differences in decisions to violate across social settings. O ne method is to compare similar activities or events occurring in social settings that vary in size, complexity, and function: e.g., fraud by families on welfare, a government agency, a university research team, a nation state in international agreement, or a small business partnership (Vaughan, 1992b; Jamison, 1996). Or, cases that hold one or two factors constant could be chosen for comparison, like Barlow's (1993) work on small business crime, which offers many insights about structure and agency. Another possibility is cross cultural case comparison of decisions to violate that targets differences in economic embeddedness, institutional, organizational, and cultural context of offenses (cf. Braithwaite, 1989: 135-138). Not only could this strategy be helpful in understanding differences in cause, but 
also might hold insights that have important implications for the challenges of global regulation (see, e.g., Gilboy, 1996; Hutter, 1996; Kagan et al., 1996).

4. Unless the research agenda includes publishing or discussing the research findings in venues where it can reach the audiences that determine legal and regulatory policies, the social control of organizations most probably will continue to prioritize a punishment strategy over other possible effective strategies that address organizational misconduct as situated action. This will be so not only because of a pervasive belief that cause rests in a consequentialist amoral calculator model and a belief in the deterrent/ retributive/ restitutive goals of punishment, but also because instituting and implementing other strategies meet with resistance by organizational actors, because punishment has greater political sex appeal, and because the causal aspects of the social context are difficult to identify and to change. All the more reason for the socio-legal community to take on the challenge of understanding decisions to violate as situated action.

\section{REFERENCES}

Abolafia, Mitchel Y. (1997) Making Markets: Opportunism and Restraint on Wall Street. $\quad$ Cambridge: 
Harvard Univ. Press.

Alexander, Jeffrey C. Bernhard Giesen, Richard Munch, and Neil J. Smelser (eds.)

(1987) The Micro-Macro Link. Berkeley: Univ. of California Press.

Allison, G raham T. (1971) The Essence of D ecision: Explaining the Cuban Missile Crisis. Boston: Little,

Brown.

Anderson, D ouglas D. (1980) "Who Owns the Regulators?" 4 Wharton Magazine 14.

Arendt, Hannah (1964) Eichmann in Jerusalem. New Y ork: Viking.

Ayres, Ian and John Braithwaite (1992) Responsive Regulation. New York: Oxford Univ. Press.

Baker, Wayne E. and Robert R. Faulkner (1993) "The Social Organization of Conspiracy: Illegal

Networks in the Heavy Electrical Equipment Industry," 58 American Sociological Review 837.

Bardach, E. and Robert A. Kagan (1982) G oing by the Book. Philadelphia: Temple Univ. Press.

Barlow, Hugh D (1993) "From Fiddle Factors to Networks of Collusion: Charting the Waters of Small Business Crime," 20 Crime, Law, and Social Change 319.

Bellah, Robert N., Richard Madsen, William M. Sullivan, Ann Swidler, and Steven Tipton (1985)

Habits of the Heart. Berkeley: Univ. of California Press.

Bourdieu, Pierre (1977) Outline of a Theory of Practice. Cambridge: Cambridge Univ. Press.

Braithwaite, John (1989) Crime, Shame, and Reintegration. Cambridge: Cambridge Univ. Press. (1985) "Taking Responsibility Seriously: Corporate Compliance Systems" in B. Fisse and

P. A. French, eds. Corrigible Corporations and Unruly Law 39. San Antonio: Trinity Univ.

Press.

and Gilbert Geis (1982) "On Theory and Action for Corporate Crime Control," $\underline{\text { Crime and }}$ Delinquency 292.

and Toni Makkai (1991) "Testing an Expected Utility Model of Corporate D eterrence," 25 Law and Society Review 7.

Calavita, Kitty, Henry N. Pontell, and Robert H. Tillman (1997) Big Money Crime: Fraud and $\quad \underline{\text { Politics }}$ 
in the Savings and Loan Crisis. Berkeley: Univ. of California Press.

Clinard, Marshall B. (1983) Corporate Ethics and Crime. Beverly Hills: Sage. and Peter C. Y eager (1980) Corporate Crime. New York: Free Press.

Coleman, James S. (1990) Foundations of Social Theory. Cambridge: Harvard Univ. Press.

Coleman, James W. (1987) "Toward an Integrated Theory of White-Collar Crime," 93 American Sociological Review 406.

Collins, Patricia Hill (1990) Black Feminist Thought. London: Harper Collins. (1991) "Learning from the Outsider Within," M.M. Fonow and J. Cook (eds.) Beyond Methodology: Feminist Scholarship as Lived Research. Bloomington: Indiana Univ. Press. Collins, Randall (1981) "On the Micro-Foundations of Macro-Sociology," 86 American Journal of Sociology 984.

Cook, Karen Schweers and Margaret Levi, eds.,(1990) The Limits of Rationality. Chicago: Univ. of Chicago Press.

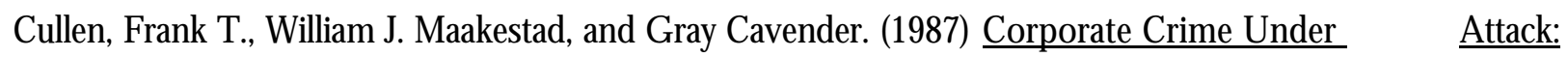
The Ford Pinto Case and Beyond. Cincinnati: Anderson.

de Tocqueville, Alexis (1969) Democracy in America. trans. G eorge Lawrence, ed. J. P. Thayer. $\quad$ New York: D oubleday.

DiMaggio, Paul J. (1997) "Culture and Cognition," 23 Annual Review of Sociology 263. (1994) "Culture and Economy," in N. J. Smelser and R. Swedberg, eds., The Handbook of Economic Sociology 27. Princeton: Princeton Univ. Press. and Walter W. Powell (1991) "Introduction," in W. W. Powell and P. J. DiMaggio, eds., The New Institutionalism in Organizational Analysis Chicago: Univ. of $\quad$ Chicago Press. Diver, Colin (1980) "A Theory of Regulatory Enforcement," 28 Public Policy 257. D odd, Nigel and Bridget Hutter (1996) "G eopolitics and the Regulation of Economic Life: The D ecline of the Nation-State?" Presented at 1996 Law and Society Association Annual Meeting, G lasgow. 
D ouglas, Mary (1987) How Institutions Think. London: Routledge and Kegan Paul.

Edelman, Lauren and Mark C. Suchman (1997) "The Legal Environment of Organizations" 23 Annual $\underline{\text { Review of Sociology } 479 .}$

Elias, Norbert (1994) Time: An Essay. O xford: Blackwell.

Emirbayer, Mustafa (1997) "What is Agency?" American Journal of Sociology (forthcoming). and Jeff Goodwin (1994) "Network Analysis, Culture, and the Problem of Agency," 99 American Journal of Sociology 1411.

Ermann, M. D avid and Richard J. Lundman (1978) "D eviant Acts by Complex O rganizations: D eviance and Social Control at the O rganizational Level of Analysis," 19 Sociological Quarterly 55.

Ewick, Patricia (1981) "Theories of O rganizational Illegality: A Reconceptualization," 2 Yale $\underline{\text { Working Paper }}$ Series. New Haven: Department of Sociology. (1985) "Redundant Regulation: Sanctioning Broker-D ealers," 7 Law and Policy 421. and Susan Silbey (1998) The Common Place of Law. Chicago: Univ. of Chicago Press.

Feldman, Martha S. (1989) O rder Without D esign. Stanford: Stanford Univ. Press. and James G. March (1981) "Information in Organizations as Sign and Symbol," 26 Administrative Science Quarterly 171.

Fine, Gary Alan (1992) "Agency, Structure, and Comparative Contexts: Toward A Synthetic Interactionism," 15 Symbolic Interaction 87.

Finney, Henry and H. R. Lesieur (1982) "A Contingency Theory of Organizational Crime," in S. B. Bacharach, ed., Research in the Sociology of Organizations. Greenwich CT: JAI Press.

Fisse, Brent and John Braithwaite (1993) Corporations, Crimes, and Accountability. Cambridge: Cambridge Univ. Press.

Fombrun, Charles (1986) "Structural Dynamics Within and Between Organizations." $31 \quad$ Administrative Science Quarterly 403. 
Friedland, Roger and Robert Alford (1991) "Bringing Society Back In: Symbols, Practices and Institutional Contradictions," in W. W. Powell and P. J. DiMaggio, eds., The New Institutionalism in Organizational Analysis 232. Chicago: Univ. of Chicago Press.

Friedman, D ebra and Michael Hechter (1988) "The Contribution of Rational Choice Theory to Macrosociological Research," 6 Sociological Theory 201.

G eis, G ilbert (1967) "The Heavy Electrical Equipment Antitrust Cases of 1961," in M. B. Clinard and R.

Quinney, Criminal Behavior Systems 139. New York: Holt, Rinehart, and Winston.

Giddens, Anthony (1984) The Constitution of Society. Berkeley: Univ. of Califormia Press.

Gilboy, Janet (1996) "Social Regulation and Business Responsibility," Presented at 1996 Law and Society Association Annual Meeting, Glasgow.

Goldhagen, D aniel Joshua (1996) Hitler's Willing Executioners. Cambridge: Harvard Univ. Press.

Gordon, Avery (1997) Ghostly Matters: Haunting and the Sociological Imagination. Minneapolis: Univ. of Minnesota Press.

Greene, Gary (1996) Occupational Crime. New Y ork: Harcourt Brace.

Gross, Edward (1980) "Organization Structure and O rganizational Crime," in G. Geis and E. Stotland, eds., White-Collar Crime: Theory and Research 52. Beverly Hills: Sage.

Grabosky, Peter N. (1989) Wayward Govemance. Woden: Australian Institute of Criminology. (1995) "Counterproductive Regulation," 23 Intemational Joumal of the Sociology of Law 347.

Granovetter, Mark (1985) "Economic Action and Social Structure: The Problem of Embeddedness," 91 American Journal of Sociology 481. (1992) "Economic Institutions as Social Constructions: A Framework for Analysis," 35 Acta Sociologica 3.

Hall, Peter M. (1987) "Interactionism and the Study of Social Organization," 28 Sociological Quarterly 1. (1995) "The Consequences of Q ualitative Analysis for Sociological Theory," 36 Sociological 
Quarterly 397.

Haraway, D onna. (1988) "Situated Knowledges: The Science Q uestion in Feminism as a Site of

D iscourse on the Privilege of Partial Perspective," 14 Feminist Studies 575.

Hawkins, Keith O . (1983) "Bargain and Bluff: Compliance Strategy and Deterrence in the Enforcement of Regulation," 5 Law and Policy 35.

(1984) Environment and Enforcement. Oxford: O xford Univ. Press.

Hays, Sharon (1994) "Structure and Agency and the Sticky Problem of Culture," 12 Sociological $\quad$ Theory 57.

Hechter, Michael (1987) Principles of Group Solidarity. Berkeley: Univ. of California Press. and Satoshi Kanazawa (1997) "Sociological Rational Choice Theory," 23 Annual Review $\quad$ of

Sociology 191.

Heimer, Carol A. (1984) "Organizational and Individual Control of Career D evelopment in Engineering Project Work," 27 Acta Sociologica 283.

(1988) "Social Structure, Psychology, and the Estimation of Risk." 14 Annual Review of Sociology 491.

Jackall, Robert (1988) Moral Mazes: The World of Corporate Managers. New York: Oxford Univ.

Press.

Jamieson, Kate (1996) "The Role of the Collective in Defining White-Collar Crime," in Helmkamp etal., eds., "D efinitional Dilemma: Can and Should There be a Universal _ D efinition of White Collar Crime?" 17.

Jepperson, Ronald (1991) "Institutions, Institutional Effects, and Institutionalism," in W.W. Powell and P. J. DiMaggio, eds., The New Institutionalism in Organizational Analysis 143. Chicago: Univ. of Chicago Press.

Kagan, Robert A., Lee Axelrad, and Charles Ruhlin (1996) "Convergence and Divergence in National Modes of Regulation: Multinational Corporations and American Adversarial Legalism," Presented at 1996 Law and Society Association Annual Meeting, Glasgow, June. 
and John T. Scholz (1984) "The 'Criminology of the Corporation' and Regulatory Enforcement

Strategies," in K. Hawkins and J. Thomas, eds., Enforcing Regulation. Boston: Kluwer-Nijhoff.

Kahneman, D aniel, Paul Slovic, and Amos Tversky, eds., (1982) Judgment Under Uncertainty:

Heuristics and Biases. Cambridge: Cambridge Univ. Press.

Katz, Jack (1979) "Legality and Equality: Plea Bargaining in the Prosecution of White-Collar and

Common Crime," 13 Law \& Society Review 431.

Kelman, Herbert C. and V. Lee Hamilton (1989) Crimes of Obedience. New Haven: Yale Univ. Press.

Knorr-Cetina, Karen and Aaron Cicourel, eds., (1981) Advances in Social Theory and $\quad$ Methodology:

Toward and Integration of Micro- and Macro-Sociology. London: Routledge and Kegan Paul.

Kram, Kathy E., Peter C. Yeager, and Gary Reed (1989) "Decisions and Dilemmas: The Ethical

Dimension in the Corporate Context." In J. E. Post, ed., 11 Research in Corporate Social

Performance and Policy 21.

Kramer, Ronald C. (1992) "State-Corporate Crime: The Space Shuttle Challenger Disaster," in $\quad$ K.

Schlegel and D. Weisburd, eds., White-Collar Crime Reconsidered . Boston: Northeastem Univ. Press.

Kunda, Gideon (1992) Engineering Culture: Control and Commitment in a High-Tech Corporation.

Philadelphia: Temple Univ. Press.

Lazega, Emmanuel (1992) The Micropolitics of Knowledge. New Y ork: Aldine.

Lindblom, Charles (1959) "The Science of Muddling Through," 19 Public Administration Review 79.

Maines, D avid R. (1977) "Social Organization and Social Structure in Symbolic Interactionist

Thought," 3 Annual Review of Sociology 235.

Mann, Kenneth, Stanton Wheeler, and Austin Sarat (1982) "Sentencing the White-Collar $\quad$ O ffender," 17

American Criminal Law Review 479.

Manning, Peter K. (1986) "The Social Reality and Social O rganization of Natural D ecision Making," 43

Washington and Lee Law Review 1291.

March, James G . and Johan P. Olsen (1979) Ambiguity and Choice in Organizations. Bergen: 
Universitetsforlaget.

and Herbert A. Simon (1958) Organizations. New York: Wiley.

and Zur Shapira (1987) "Management Perspectives on Risk and Risk Taking," 33 Management

Science 1404.

Martin, Joanne (1992) Cultures in Organizations: Three Perspectives. New Y ork: Oxford Univ. Press.

McCurdy, Howard (1993) Inside NASA: High Technology and Organizational Change in the U.S. Space

Program. Baltimore: Johns Hopkins Univ. Press.

Meiksins, Peter (1988) "The Revolt of the Engineers Reconsidered," 29 Technology and Culture 219.

Meyer, John and Brian Rowan (1977) "Institutionalized Organizations: Formal Structure as Myth ～and

Ceremony." 83 American Journal of Sociology 340.

Mileti, Dennis, John Sorenson, and William Bogard (1985) Evacuation Decision-Making: Process and

Uncertainty. Oak Ridge, Tenn.: O ak Ridge National Laboratory.

Morrill, Calvin, Ellen Snyderman, and Edwin J. Dawson (1997) "It's Not What You Do, But Who You

Are: Informal Social Control, Social Status, and Normative Seriousness in Organizations," 12 Sociological

Forum 519.

Paternoster, Ray and Sally S. Simpson (1993) "A Rational Choice Theory of Corporate Crime," in R. V.

Clarke and M. Felson, eds., 5 Routine Activity and Rational Choice: Advances in $\quad$ Criminological Theory

37. New Brunswick: Transaction Press.

(1996) "Testing a Rational Choice Model of Corporate Crime,"30 Law and Society Review 549.

Passas, Nikos (1990) "Anomie and Corporate D eviance," 14 Contemporary Crises 157.

(1997) "The BCCI Case," in R. Agnew and N. Passas, eds., The Future of Anomie Theory. Boston:

Northeastem Univ. Press.

Petroski, Henri (1985) To Engineer is Human: The Role of Failure in Successful D esign New York: St.

Martin's.

Pfeffer, Jeffrey and G erald Salancik (1978) The External Control of Organizations. New Y ork: $\quad$ Harper 
and Row.

Powell, Walter W. and Paul J. DiMaggio, eds., (1991) The New Institutionalism in Organizational $\underline{\text { Analysis. }}$ Chicago: Univ. of Chicago Press.

Presidential Commission on the Space Shuttle Challenger Accident (1986) Report to the President by the

Presidential Commission on the Space Shuttle Challenger Accident. $5 \quad$ vols. Washington, D.C.:

Government Printing Office.

Punch, Maurice (1996) Dirty Business: Exploring Corporate Misconduct. London: Sage.

Q uinney, Richard (1963) "O ccupational Structure and Criminal Behavior: Prescription Violation by Retail Pharmacists," 11 Social Problems 179.

Ragin, Charles C. (1994) Constructing Social Research. Beverly Hills: Pine Forge Press.

Reed, Gary E. and Peter Cleary Y eager (1996) "Organizational Offending and NeoClassical Criminology: Challenging the Reach of a General Theory of Crime," 3 Criminology 357. Reiss, Albert J. Jr. (1984) "Selecting Strategies of Social Control Over Organizational Life," in $\quad$ K. Hawkins and J. M. Thomas, eds., Enforcing Regulation. Boston: Kluwer-Nijhoff. (1966) "The Study of Deviant Behavior: Where the Action is." 32 Ohio Valley Sociologist 60.

Romzek, Barbara S. and Melvin J. D ubnick (1987) "Accountability in the Public Sector: Lessons from the Challenger Tragedy," 47 Public Administration Review 227.

Schlegel, Kip (1990) Just D eserts for Corporate Criminals. Boston: Northeastern Univ. Press.

Sewell, William H., Jr. (1992) "A Theory of Structure: D uality, Agency, and Transformations," 98 American Journal of Sociology 1.

Shapiro, Susan (1984) Wayward Capitalists. New Haven: Yale Univ. Press.

(1987) "The Social Control of Impersonal Trust." 93 American Journal of Sociology 646.

Simpson, Sally S. (1986) "The Decomposition of Antitrust: Testing a Multi-level Longitudinal _ Model of Profit Squeeze," 51 American Sociological Review 859. (1992) "Corporate Crime D eterrence and Corporate-Control Policies," in K. Schlegel and D. 
Weisburd, White-Collar Crime Reconsidered. Boston: Northeastem Univ. Press: 289. (1998) Why Corporations Obey the Law. New York: Cambridge Univ. Press. and Christopher Koper (1992) "D eterring Corporate Crime," 30 Criminology 347.

Simon, Herbert A. (1976) Administrative Behavior: A Study of D ecision-Making Processes in Administrative Organizations. 3rd. ed. New Y ork: Free Press.

Smith, D orothy (1987) The Everyday World as Problematic. Boston: Northeastern Univ. Press.

Staw, Barry M. and Eugene Swajkowski (1975) "The Scarcity Munificence Component of Organizational Environments and the Commission of Illegal Acts," 20 Administrative $\quad$ Science Quarterly 345.

Stinchcombe, Arthur L. (1965) "Social Structure and Organizations," in J. G. March, ed., $\quad$ Handbook of Organizations. Chicago: Rand-McNally.

Stone, Christopher D . (1975) Where the Law Ends. New York: Harper and Row.

Sutherland, Edwin H. (1949) White-Collar Crime. New York: D ryden Press.

U.S. Congress. House. (1986) Investigation of the Challenger Accident: Hearings; Report. 3 vols.

Washington, D .C.: Government Printing Office.

Van Maanen, John and Steve Barley (1985) "Cultural Organization: Fragments of a Theory," in Peter J.

Frost, Larry F. Moore, Meryl Ries Louis, Craig Lundberg, and Joanne Martin ～eds, Organizational

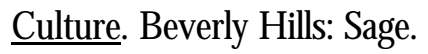
and Edgar H. Schein (1979) "Toward a Theory of O rganizational Socialization," in B. Staw and L. L.

Cummings, eds., Research in Organizational Behavior. Greenwich CT: JAI Press.

Vaughan, Diane (1983) Controlling Unlawful Organizational Behavior. Chicago: Univ. of Chicago Press. (1990) "Autonomy, Interdependence, and Social Control: NASA and the Space Shuttle Challenger," 35 Administrative Science Quarterly 225. (1992a) "The Macro-Micro Connection in 'White-Collar Crime,"' in K. Schlegel and D. Weisburd, eds., White-Collar Crime Reconsidered. Boston: Northeastern Univ. Press. (1992b) "Theory Elaboration: The Heuristics of Case Analysis," in C. Ragin and H. S. Becker, 
eds., What is a Case? Exploring the Foundations of Social Inquiry. New York: Cambridge Univ. Press. (1996) The Challenger Launch Decision: Risky Technology, Culture, and D eviance at $\quad$ NASA.

Chicago: Univ. of Chicago Press.

(1997) "Anomie Theory and Organizations: Culture and the Normalization of D eviance at NASA,"

in N. Passas and R. M. Agnew, eds., The Future of Anomie Theory. Boston: Northeastern Univ. Press. (1998) "The Macro-Micro Connection, Culture, and Boundary Work: Toward the Social Control of Organizations," in R. Kagan, P. Ewick, and A. Sarat, eds., Social Science, Legal Scholarship, and the Law. Chicago: Univ. of Chicago Press and Russell Sage, forthcoming.

Weick, Karl E. (1995) Sensemaking in Organizations. Thousand Oaks: Sage. (1979) The Social Psychology of Organizing. Reading, MA: Addison-Wesley.

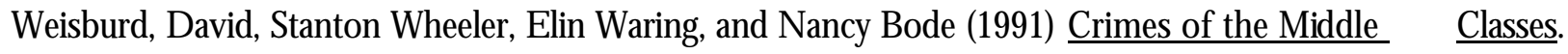
New Haven: Yale Univ. Press.

, Elin Waring, and Ellen Chayet (1995) "Specific Deterrence in a Sample of O ffenders Convicted of White-Collar Crimes," 33 Criminology 587.

Wheeler, Stanton (1983) "White-Collar Crime: History of an Idea." in Leonard Orland (ed.) Corporate and White Collar Crime: An Anthology 95. Cincinnati: Anderson.

_-_-_ and Mitchell Rothman (1982) "The O rganization as Weapon in White-Collar Crime," 80 Michigan Law Review 1403.

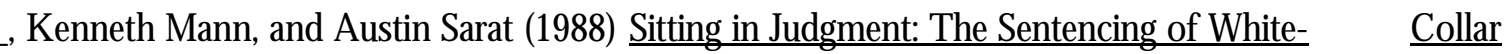

Offenders. New Haven: Yale Univ. Press.

Wildavsky, Aaron (1987) "Choosing Preferences by Constructing Institutions: A Cultural Theory of

Preference Formation," 81 American Political Science Review 3.

Wilensky, Harold (1967) Organizational Intelligence: Knowledge and Policy in Government and Industry. New York: Basic Books.

Wynne, Brian (1988) "Unruly Technology: Practical Rules, Impractical D iscourses, and Public 
Understanding," 18 Social Studies of Science 147.

Zerubavel, Eviatar (1997) Social Mindscapes: Toward A Cognitive Sociology. Cambridge: Harvard Univ.

Press.

Zimring, Frank and Gordon J. Hawkins (1973) Deterrence: The Legal Threat in Crime Control. Chicago:

Univ. of Chicago Press.

Zucker, Lynn (1977) "The Role of Institutionalization in Cultural Persistence," 42 American Sociological

Review 726.

\section{NOTES}

i. I am grateful for a 1996-1997 National Endowment for the Humanities Fellowship, Institute for Advanced Study, Princeton NJ for the support that enabled me to write this paper. Thanks also to Michael Hechter, Robert A. Kagan, and three anonymous reviewers for comments that helped me clarify my argument.

ii. An internal memo documenting the calculations of costs and benefits surfaced in the investigation of the Ford Motor Company's decision to manufacture a flawed Pinto design. It showed Ford officials calculated the cost of redesigning the Pinto to eliminate the flaw and the cost of retooling to manufacture a new, safe design. Then they calculated the probability of accidents and loss of life, estimating the value of a human life at $\$ 200,000$. The cost of redesign far outweighed the cost of accidents. Production went forward. But Frank Cullen, author of the authoritative research on the case noted, "It may be that they did so because they were conforming to norms of the organization culture and the competitive auto industry, so it was not a deviant act, in their opinion, but simply good business." (Personal communication, November, 1994). See Frank T. Cullen, William J. Maakestad, and G ray Cavender, Corporate Crime Under Attack: The Ford Pinto Case and Beyond. Cincinnati: Anderson, 1987. 